\title{
A Research on Machinability of Bio Implant by Electric Discharge Machining Process
}

\author{
Sivakumar.S, Adamkhan.M, Winowlin Jappes .J.T
}

\begin{abstract}
Increasing demand in industries to manufacturing the complex geometric shape and hard materials parts is extremely difficult to cut by the conventional machining process. The non-conventional machine is used for the manufacturing of $3 D$ complex and geometry shapes without compromise the required specification. Electro discharge machining (EDM) is a non-traditional machining process, which is very widely used in recent days. EDM process is electrical and thermal energy generated between work piece and an electrode. The major applications are dies, moulds, aerospace parts, automotive industry, and surgical components. The human implant materials like Stainless Steel, Titanium and Co-Cr based alloys are widely used in biomedical fields. This paper shows that fundamental studies on electrical discharge machining (EDM), Wire electrical discharge machining (WEDM) and human implant materials with newly developed advance technologies in the current scenario.
\end{abstract}

Keywords : EDM, WEDM, Implant, Stainless steel, Titanium, Co-Cr alloy.

\section{INTRODUCTION}

\section{A. Electrical Discharge Machine}

Electrical discharge machining (EDM) is one of the non-traditional process used for manufacturing varies parts in industries. It is producing micro and macro dimensions products economically and accurately. In current industries developed machining concept like EDM with computer numerical control (CNC) \& four axis servo- controllers in EDM machine tool. EDM is the process for manufacture of complex 3D shapes the current research is focused on this process.

EDM is a process to machine hard material easily without compromise requirements. The conductive work piece only used for machining process, because the electrical and thermal energy to remove the materials by melting \& evaporation [1]. The tool and work piece are maintain gap to generate a spark and remove the material. The tool immersion directly placed in work piece to produce the final shape. The following merits are avoid cutting force, avoid burrs on work

Revised Manuscript Received on December 05, 2019.

* Correspondence Author

S.Sivakumar, Department of Mechanical Engineering, School of Automotive and Mechanical Engineering, Centre for Surface Engineering Kalasalingam Academy of Research \& Education, Virudhunagar Dist, Tamilnadu, India. Email: sivakumar@klu.ac.in

Adamkhan.M*, Department of Mechanical Engineering, School of Automotive and Mechanical Engineering, Centre for Surface Engineering Kalasalingam Academy of Research \& Education, Virudhunagar Dist, Tamilnadu, India. Email: adamkhan.m@klu.ac.in

Winowlin Jappes .J.T, Department of Mechanical Engineering, School of Automotive and Mechanical Engineering, Centre for Surface Engineering Kalasalingam Academy of Research \& Education, Virudhunagar Dist, Tamilnadu, India. Email: winowlin@klu.ac.in materials, cut any conductive hard materials, corrosion free on machine setup, etc. the limitations are tool wear and high machining time [2, 3]. Table I selection of tool Materials in EDM. Tool materials such as brass, copper, tungsten carbide (WC), tungsten copper alloy $(\mathrm{Cu} \mathrm{W})$, cast iron, steel, zinc based alloy and copper graphite are used as electrode material for EDM because of their good wear characteristics and their ability to be machined in cutting process [4].

Table- I: Selection of tool materials in EDM [4]

\begin{tabular}{|c|c|c|c|c|}
\hline S.NO & $\begin{array}{c}\text { Electrode } \\
\text { Material }\end{array}$ & $\begin{array}{c}\text { Material } \\
\text { removal rate }\end{array}$ & Fabrication & Cost \\
\hline 1 & Copper & High on rough & Easy & High \\
\hline 2 & Brass & High on finish & Easy & low \\
\hline 3 & Tungsten & low & Difficult & High \\
\hline 4 & $\begin{array}{l}\text { Tungsten } \\
\text { copper alloy }\end{array}$ & low & Difficult & High \\
\hline 5 & Cast iron & low & Easy & low \\
\hline 6 & Steel & low & Easy & low \\
\hline 7 & $\begin{array}{l}\text { Zinc based } \\
\text { alloy }\end{array}$ & High on rough & Easy & High \\
\hline 8 & $\begin{array}{l}\text { Copper } \\
\text { graphite }\end{array}$ & High on finish & Difficult & High \\
\hline
\end{tabular}

Work piece materials such as, grade of hard steel, tungsten carbide, titaninum, inconel etc. The desired properties of work piece for maximum materials removal are low thermal conductivity, high electrical conductivity, low melting and boiling point etc.

The tool and work piece are maintained gap and act as an insulator using dielectric medium. When the applied electric field reaches the dielectric strength of medium, dielectric will break down to cause large current to flow. Commonly used dielectrics are air, liquid or gas. The basic classification of dielectric is polar dielectric and non-polar dielectric [5]. A polar dielectric will have a dipole and so it gets polarized very fast on application of electric field. Water and ammonia are examples of polar dielectric medium. Alternatively, non-polar dielectric does not have a dipole and hence have larger polarization time. Benzene, mineral oils, EDM oil, etc., are all non-polar dielectric media. The necessary properties of a good dielectric are low viscosity, high flash point, low dielectric strength, low volatility, etc [6] an important element of EDM process is power supply and it is based on either resistance capacitance (RC) circuit or transistor circuit [7] the various elements of EDM are depicted by a schematic diagram in Fig 1. Along with these elements, a good EDM machine will require a servo control mechanism. This mechanism is based on limiting reference voltage value to maintain a constant gap [8].

Published By: Blue Eyes Intelligence Engineering 
It is well known that for a given applied voltage, the breakdown voltage increases or decreases with the gap. When the tool is closer to the workpiece, the breakdown voltage will be smaller than the reference voltage and hence the servo control will retract the tool away from the workpiece.

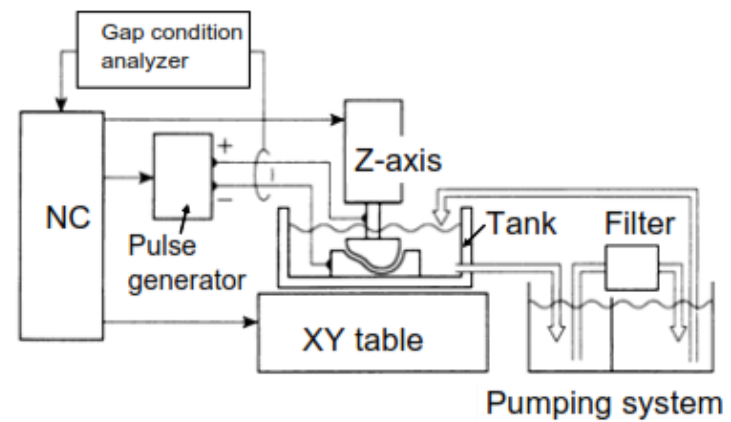

Fig. 1. Sinking electrical discharge machine [2]

While when the gap is large, the breakdown voltage will also be large and so the servo control will feed the tool closer to the workpiece till the breakdown voltage reaches the reference value. This mechanism maintains a constant gap during the process and ensures continuous normal discharge [9]

\section{B. Wire Electrical Discharge Machine}

In recent years is one of the most popular techniques of non-conventional machining to manufacturing parts. It can be produced small radius concave and convex parts. The machining process like wire acts as tool passing current to cut work materials by generation of spark. [10]. Experiments made on titanium materials the effect of input parameters such us pulse on time. Pulse off time, voltage, wire feed, current and wire tension. In this research observed that pulse width and current are affect the surface roughness and cutting speed [11]. The superior mechanical property materials Inconel 718 machined by WEDM. The pulse on time was generated the discharge energy. Increasing and decreasing the energy mode to cut high and low material removal in work piece [12]. The cutting rate affected another factor like voltage and pulse off time. The gap between work piece and tool is maintained depends upon the voltage parameter. The velocity of electrons is increasing and decreasing to given voltage level. The higher voltage increasing speed of electrons to increases the gap and decreases cutting rate. The lower voltage is decreasing speed of electrons to decrease the gap and increases cutting rate [13]. After discharge energy the pulse off time is allowed to dielectric fluid remove the eroded material during the off cycle [14]. S.Abdulkarrem et al, compare and analyzed that surface qualities in wet and dry WEDM. A wet WEDM surface quality is better than Dry WEDM. Oliver et al reported that compare copper - brass electrode wire and molybdenum wires in WEDM process [15]. The quality of surface finish analyzed in machined samples [16]. Farnaz et al investigated the zinc coated and uncoated brass wire in WEDM process. The surface roughness, cracks and craters decreases with help of zinc coated brass wire [17]. Fabio et al reported that deionised water and hydrocarbon based di electric fluids are compared in WEDM process. In this investigation the deionised water is found to be more suitable for machining steel. Because the deposition of carbon over the machined surface has been significantly reduced while using deionised water [18]. Schematic diagram of WEDM fig 2.

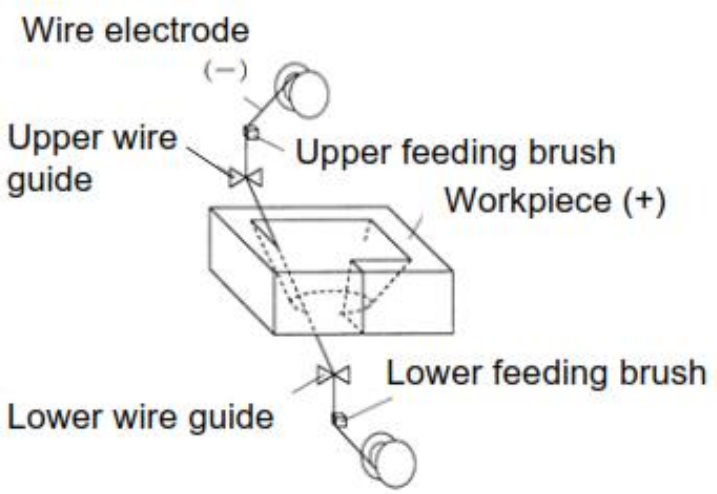

Fig. 2. Schematic diagram of WEDM [2]

\section{Implant Materials}

Bone is help to safe human organs, protect against external loading and link frame work support to kinematic motion [19]. The implant is support to help fast healing, tissue formation triggering and regain original shape [20]. Shalabi review that the effect of surface roughness to increase and decrease bone healing [21]. Biocompatibility implant materials only allow using human living systems. Compatible implant minimum shear stress reacted with bone and tissue [22].After implantation the protein layer surrounded with implant and provide link between material surface and biological responses [23]. In the field of biomedical industries following materials used in human body such as metals, ceramics, glasses, polymers and composites[24]. Common metallic biomaterials are stainless steel, Co based alloy and titanium based alloy. Implant grade stainless steel 316L are manufactured special way such us vacuum melting (VM), Vacuum arc re-melting (VAR) or electroslag refining (ESR) are used to increasing corrosion resistance. Most widely used for bone screws, bone plates, rods etc [25]. The Co based alloy has higher wear resistance than that of both stainless steel and titanium alloy. Co based alloy are used to fabricate knee and hip joint for higher strength [26]. Titanium based alloy has a low density, high ductility and high strength material. The titanium grades are varies depends upon the minimum difference between oxygen and iron content. It is very effective binding with fractured bone, corrosive resistance, avoid toxic formation and long period of time in human body [27].

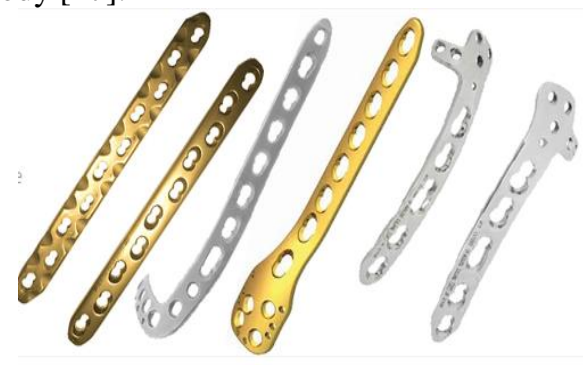

Fig. 3. Types of bone implant materials used in human 


\section{DISCUSSION}

In this literature review that to explore in detailed about electrical discharge machining process, wire electrical discharge machining process and commercially available implant. The mechanical and biological properties, bone and tissues formations such as those previously discussed. The further discussions are electrical discharge machining process on implant materials.

Stainless steel material one of the cheapest implant used for biomedical application. In this study stainless steel $316 \mathrm{~L}$ and copper impregnated graphite act as work piece and electrode. The input process parameter influences investigated in electrical discharge machining process [31].Durairaj et al optimized and analyzed that effect of process parameters to obtained good surface qualities and kerf width using WEDM process [10]. Raju et al found that WEDM optimal parametric combination of input parameters such us pulse on time, peak current and servo voltage for obtained good surface finish [32].Co-Cr alloy and grade II cpTi alloys are machined two different machining processes such as EDM and conventional machine finally analyzed the corrosion resistance [33]. The developed finite element model and develop constitutive model on Co-Cr alloy [34]. In this experimental study SMA are Ti50Ni50 and Ti50Ni49.5Cr0.5 act as a work material pure titanium pipe act as electrode. Nitrogen gas is used as a dielectric medium in dry EDM process. The $\mathrm{Cr}$ was added to decrease the martensite temperature and found that low surface roughness [35].Compare and optimized machining process parameter on stainless steel and titanium implant using EDM process. The duty cycle and pulse on time major contribution on MRR, tool wear and radial overcut [36]. The colorful oxide film added successfully on titanium using EDM process. The different colors produce on titanium surface with change of voltage EDM process [37]. Ti6Al4V alloy were studied different particle size $(3,10,15 \mu \mathrm{m})$ special graphite electrode using EDM. The observed that 10 $\mu \mathrm{m}$ graphite electrode shows good result in MRR, surface roughness and volumetric wear [38]. The $\mathrm{TiNiCu}$ shape memory alloy invested the effect of process parameter using WEDM.The increasing pulse on time, peak current and wire feed are increases the surface roughness, MRR and tool wear, The better surface finish observed that low pulse on time, current and high pulse off time [39]. The surface roughness major role plays in cell attachment and bone growth in bone-dental implant [40].

The five different dielectric fluids were investigated such as gas, air, oxygen, deionized water and oil. It is observed different carter formed in every dielectric fluid machined surface [41]. Investigated the silicon powder mixed dielectric fluid of EDM significantly reduces surface defects and increased surface quality [42]. The two mechanical surface treatments are ultrasonic and abrasive blasting to improve surface integrity and reduce damage EDM machined samples [43]. The Ni-Ti based shape memory alloy machined by hybrid machining process like laser and micro-EDM. It is suggested that high MRR using laser process and good surface quality using mirco-EDM [44]. The mathematical model was developed and optimized machining parameters on nitinol shape memory alloy using WEDM process [45].

\section{CONCLUSION}

The introduction of EDM is an electro thermal non-conventional machining process discussed in detailed. In current industries, high hardened materials are developed in research areas. It is easy to manufacture hard materials economically and accurately. EDM process essential and valuable role in manufacturing tool room parts.

Produced high complex and concave shapes accurately in the WEDM process. The effect of process parameter major contribution in output responses such as surface roughness and MRR. It is found that effective and efficient machining for hard materials.

In biomedical implants fundamentals, research and development of metallic materials studied in detail. The Selection of materials is very important to avoid metal -related toxicity and corrosion in the body. The development of the implant is highly compatible for a living system.

\section{REFERENCES}

1. Mikell P. Groover, Fundamentals of Modern Manufacturing Materials, Processes, and Systems, John Wiley and Sons Inc., 2010

2. M. Kunieda, B. Lauwers, K. P. Rajurkar and B. M. Schumacher, Advancing EDM through Fundamental Insight into the Process, CIRP Annals, vol. 54, 2005, pp. 64-87.

3. J. W. Marry, J. Sun, D. V. Patil, T.A. Wood and A.T. Clare, Physical and electrical characteristics of EDM debris, Journal of materials processing technology, vol. 229, 2016, pp. 54-60.

4. Sharanjit Singh and Arvind Bhardwaj, Review to EDM by Using Water and Powder-Mixed Dielectric Fluid, Journal of minerals and materials characterization and engineering, vol. 10, 2011, pp. 199-230.

5. S.Chakraborty, V.Dey and S.K. Ghosh, A review on the use of dielectric fluids and their effects in electrical discharge machining characteristics, Precision Engineering, vol. 40, 2015, pp.1-6.

6. V.K. Jain, Advanced Machining Processes, Allied Publishers Pvt. Ltd, 2005.

7. M.P Jahan, Y.S. Wong and M. A. Rahman, study on the quality micro-hole machining of tungsten carbide by micro-EDM process using transistor and RC-type pulse generator, Journal of Materials Processing Technology, vol. 209, 2009, pp. 1706-1716.

8. Baoyang Jiang, Shuhuai Lan, Jun $\mathrm{Ni}$ and Zhaoyang Zhang, Experimental investigation of spark generation in electrochemical discharge machining of of non-conducting materials, Journal of Materials Processing Technology, vol. 214, 2014, pp. 892-898.

9. P.M. Chinamaya, Siba Shankar Mahapatra and Manas Ranjan Singh, An Experimental Investigation of Machinability of Inconel 718 in Abstract Electrical Discharge Machining, Procedia Materials Science, vol. 6,2014 , pp. $605-611$.

10. M. Durairaj, D. Sudharsun and N. Swamynathan, Analysis of Process Parameters in Wire EDM with Stainless Steel using Single Objective Taguchi Method and Multi Objective Grey Relational Grade, Procedia Engineering, vol. 64 , pp. 868-877, 2013.

11. Sujeet Kumar Chaubey and Neelesh Kumar Jain, Investigations on surface quality of WEDM manufactured meso bevel and helical gears, Materials and Manufacturing Processes, vol. 33, 2018.

12. L. Li, X.T. Wei, Y.B. Guo, W. Li, and J.F. Liu, Surface Integrity of Inconel 718 by Wire-EDM at Different Energy Modes, Journal of Materials Engineering and Performance, vol. 23, 2014, pp. 3051-3057.

13. M. Manjaiah, F. Rudolph, Laubscher, Anil Kumar and S. Basavarajappa, Parametric optimization of MRR and surface roughness in wire electro discharge machining (WEDM) of D2 steel using Taguchi-based utility approach, International journal of Mechanical and materials engineering, vol. 11, 2016.

14. Vivek Aggarwal, Sehijpal Singh Khangura, R. K. Garg, Parametric modeling and optimization for wire electrical discharge machining of Inconel 718 using response surface methodology, International Journal of Advanced Manufacturing Technology, vol. 79, 2015, pp. 31-47. 
15. S. Abdulkareem, A.A. Khan and Z.M. Zain, Effect of machining parameters on surface roughness during Wet and Dry Wire-EDM of stainless steel, Journal of applied science, vol.11, 2011, pp. 1867-1871.

16. S. Oliver Nesa Raj and S. Prabhu, Modeling and analysis of titanium alloy in wirecut EDM using Grey relation coupled with principle component analysis, Australian Journal of Mechanical Engineering, vol. 15, 2017, pp.198-209.

17. Farnaz Nourbakhsh, K. P. Rajurkar, A. P. Malshe and Jian Cao, Wire electro-discharge machining of titanium alloy, Procedia CIRP, vol 5 , 2013, pp. 13-18.

18. Fábio N. Leão and Ian R. Pashby, A review on the use of environmentally-friendly dielectric fluids in electrical discharge machining, Journal of Materials Processing Technology, vol. 149 , 2004, pp. 341-346.

19. Damien Lacroix, Bone composition and structure, Biomechanical aspects of bone repair, Elsevier Ltd, $2^{\text {nd }}$ Edition, 2019, pp. 53-64.

20. M.P. kendell, A. Ashley and M.B. Serena, Properties and characterization of bone repair materials, Biomechanical aspects of bone repair, , Elsevier Ltd, $2^{\text {nd }}$ Edition, 2019, pp. 65-102.

21. M.M. Shalabi, A. Gortemaker, M.A. Van't Hof, J.A. Jansen and N.H.J. Creugers, Implant Surface Roughness and Bone Healing: a Systematic Review, National center of biotechnology information, vol. 85, 2006, pp. 496-500.

22. S.B. Goodman, E. Gomez Barrena, M. Takagi and Y.T. Konttinen, Biocompatibility of total joint replacements: A review, National center of biotechnology information, vol. 90, 2009, pp. 603-618.

23. J.W. Cameron, E.C Richard, I.L. David, and J.P. Mark, Mediation of biomaterial-cell interaction by absorbed proteins: A review, Tissue Engineering, vol. 11,2005.

24. Mythili Prakasam, Janis Locs, Kristine Salma-Ancane, Dagnija Loca, Alain Largeteau and Liga Berzina-Cimdina, Biodegradable Materials and Metallic Implants-A Review, journal of functional biomaterials , vol. 8, 2017, pp. 1-15.

25. J.L. González-Carrasco, S.C. Cifuentes Cuellar and M. Lieblich Rodríguez, Metals, Bone Repair Biomaterials, Elsevier Ltd, $2^{\text {nd }}$ Edition, 2019, pp. 103-140.

26. Mohamed A. Hussein, Abdul Samad Mohammed and Naser Al-Aqeeli, Wear Characteristics of Metallic Biomaterials: A Review, Materials, vol 8, 2015, pp-2749-2768.

27. Matej Balazic and Januz Kopac, Review: titanium and titanium alloy applications in medicine, International journal of nano and biomaterials,vol. 1, 2007.

28. Reham B. Osman and Michael V. Swain, A Critical Review of Dental Implant Materials with an Emphasis on Titanium versus Zirconia, Materials, vol. 8, 2015, pp. 932-958.

29. D. Stoeckel, Nitinol medical devices and implants, Min Invas Ther \& Allied Technol, vol.9, 2000, pp. 81-88.

30. Vamsi Krishna Balla, Susmita Bose, Neal M. Davies and Amit Bandyopadhyay, Tantalum-A bioactive metal for implants, Biological and biomedical materials, vol.62, 2010, pp.61-64.

31. Safian Sharif, Wahaizad Safiei, A. F. Mansor, M. H. M. Isa and R. M. Saad, Experimental study of electrical discharge machine (die sinking) on stainless steel $316 \mathrm{~L}$ using design of experiment, Procedia manufacturing, vol. 2, 2015, pp. 147-152.

32. P.Raju, M.M.M. Sarcar and B.Satyanarayana, Optimization of wire electric discharge machining parameters for surface roughness on 316 L stainless steel using full factorial experimental design, procedia materials science, vol. 5, 2014, pp.1670-1676.

33. Argyro Ntasi, Wolf Dieter Mueller, George Eliades and Spiros Zinelis, The effect of Electro Discharge Machining (EDM) on the corrosion resistance of dental alloys, Dental Materials, vol. 26, 2010, pp.e237-e245.

34. D. Trimble, H. Shipley, L. Lea, A. Jardine, G.E. O'Donnell, Constitutive analysis of biomedical grade Co-27Cr-5Mo alloy at high strain rates, Materials science and engineering A, vol. 628, pp. 466-474. 2017.

35. Tyau-Song Huang, Shy-Feng Hsieh, Sung-Long Chen, Ming-Hong Lin Wei-Tse Chang and Shih-Fu Ou, Surface modification of TiNi-based shape memory alloys by dry electrical discharge machining, journal of materials processing technology, vol.221, 2015, pp.279-284.

36. Anshuman Kumar Sahu, Pragyan Paramita Mohanty and Sarat Kumar Sahoo, Electro Discharge Machining of Ti-Alloy (Ti6Al4V) and 316L Stainless Steel and Optimization of Process Parameters by Grey Relational Analysis (GRA) Method, Advances in 3D Printing \& Additive Manufacturing Technologies, 2016, pp. 65-78.
37. Y.Y. Tsai, P.L. Song and J.S. Chung Fang, Colorful Oxide film formation on titanium by using EDM process, International journal of precision engineering and manufacturing, vol. 14, 2013, pp 1933-1937.

38. Fred L. Amorim, Leandro J. Stedile, Ricardo D. Torres, Paulo C. Soares, and Carlos A. Henning Laurindo, Performance and Surface Integrity of Ti6Al4V After Sinking EDM with Special Graphite Electrodes, Journal of Materials Engineering and Performance, vol. 23, 2014, pp. 1480-1488.

39. M. Manjaiah, S. Narendranath and S. Basavarajappa, Wire Electro Discharge Machining Performance of TiNiCu Shape Memory Alloy, silicon, vol.8, 2016, pp. 467-475.

40. C.N. Elias, J.H.C. Lima, M.P.Da Sliva, and C.A. Muller, Titanium Dental Implants With Different Morphologies, vol. 18, 2002, pp. 46-49.

41. Yanzhen Zhang, Yonghong Liu, Yang Shen, Renjie Ji, Zhen Li and Chao Zheng, Investigation on the influence of the dielectrics on the material removal characteristics of EDM, Journal of Materials Processing Technology, vol. 214, 2014, pp. 1052-1061.

42. H. K Chander Prakash, Kansal, B. S. Pabla and Sanjeev Puri, Experimental Investigations in Powder Mixed Electric Discharge Machining of Ti-35Nb-7Ta-5Zr $\beta$ - Titanium Alloy, Materials and manufacturing process, vol. 32, 2017, pp. 274-285.

43. J. X. Deng and T. C. Lee, Techniques For Improved Surface Integrity Of Electro discharge Machined Ceramic Composites, Surface engineering, vol. 16, 2000, pp.411-414.

44. A. Al-Ahmari, M. Sarvar Rasheed, Muneer Khan Mohammed and T. Saleh, A Hybrid Machining Process Combining Micro-EDM and Laser Beam Machining of Nickel-Titanium Based Shape Memory Alloy, Materials and manufacturing process, vol. 31, 2016, pp. 447-455.

45. HimadriMajumder and KalipadaMaity, Prediction and optimization of surface roughness and micro-hardness using grnn and MOORA-fuzzy-a MCDM approach for nitinol in WEDM, Measurement, vol. 118, 2018, pp.1-13.

\section{AUTHORS PROFILE}

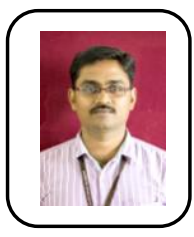

S.Sivakumar is a Doctoral scholar doing research in the area of advanced materials - manufacturing and surface engineering. His received Bachelor (B.E.) and Master Degree (M.E.) from Anna University, Chennai in the specialization of Automobile and CAD/CAM.

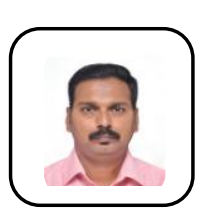

Dr. Adam Khan M is a Post-Doctoral Researcher from the Department of Mechanical and Industrial Engineering Technology, University of Johannesburg, South Africa. He received his Doctoral Degree from National Institute of Technology, Tiruchirappalli, India for his research in Surface Engineering studies on high temperature materials. His Bachelor (B.E.) and Master Degree (M.E.) from Anna University, Chennai in the specialization of Production and Design. Dr. Adam Khan research is focused on surface engineering and metallurgical analysis on processed materials. He has published 38 technical articles in different journals of international repute.

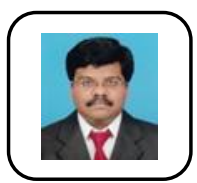

Dr. Winowlin Jappes J T graduated in 1997 from Manonmaniam Sunderanar University, India in Mechanical Engineering. In 1999, he has completed his masters in Production Engineering from Annamalai University. He completed his Ph.D degree in 2004 in the area of Composite Deposition at Indian Institute of Technology Madras, Chennai. He has completed three DST funded research projects and published more than 125 research articles which include 65 International Journal papers. Currently, he is working as Senior Professor in Kalasalingam University, India. His research interest includes high performance composite materials, machining of hard materials, optimization techniques, etc. At present, he is working as Professor and Dean, School of Automotive and Mechanical Engineering, Kalasalingam Academy of Research and Education, 